\title{
Left Enlargement is an Early Signs of Hypertensive Heart Disease Atrial
}

\author{
Hanan K. G. Altalhi ${ }^{1 *}$, Asgad A. Abdalgbar ${ }^{1,2}$ \\ ${ }^{1}$ Faculty of Medicine, University of Omar El mukhtar, Albayda, Libya \\ ${ }^{2}$ Faculty of Medical Technology, University of Omar El Mukhtar, Albayda, Libya
}

*Corresponding Author: Hanan K. G. Altalhi, Faculty of Medicine, University of Omar El mukhtar, Albayda, Libya, Email: hnangk@yahoo.com

\begin{abstract}
Systemic hypertension often leads to left ventricular hypertrophy, congestive heart failure and death (Kannel WB, et al. 1972).

How to identify the early signs of hypertensive heart is the key to block or reverse the process of heart failure.

The aim of this study is to evaluate the predictive value of left atrial (LA) enlargement in the early stage of hypertensive heart disease and to explore the correlation between LA enlargement and heart failure with normal ejection fraction (HFnEF).
\end{abstract}

Method: This is case control study of 52 patients admitted to the hospital, 26 patients with history of hypertension (case subject) and 26 without history of hypertension were included as (Control subject). All participant underwent the standard examination and testing as well as Echocardiography (measurement of left atrial dimension, Ejection fraction, Left atrial volume, mitral inflow, Left ventricle mass).

Patient with valvular heart disease, atrial fibrillation or coronary disease were excluded.

Result: The mean age was $69 \pm 18$ year in the hypertensive patients and $66 \pm 17$ year in control group. The LA dimension of hypertensive group (38 \pm 5.2$)$ was significantly greater than control group (34.5 \pm 3.4 ); $P<0.001$ ) $L A V$ and LAVI were significantly higher in hypertensive group than control group $(55.5 \pm 15.5$ vs $41.7 \pm 13.8$ $P<0.001 \quad 28.5 \pm 7.2$ vs $22.2, P<0.001$ respectively).

LVM and LVMI were significantly higher in hypertensive group than in control group (174 \pm 46 VS $150 \pm 31$ G, $P<0.0001,106 \pm 24$ VS 95 $\pm 16, P=0.001$ ).

Conclusion: We conclude that Echocardiographic LA enlargement may be an early sign of hypertensive heart disease in patient with no other clear cause of left atrial enlargement.

Keywords: Left atrium (LA), left ventricular systolic function (LVSF), left ventricular mass index (LVMI), Echocardiography (Echo), heart failure with normal ejection fraction HFnEF.

\section{INTRODUCTION}

Left atrial enlargement (LAE) is risk factor for paroxysmal supraventricular embolism and death (Jessup M, et al 2007; Aurigemma GP, et al 2004; Zile MR, et al 2004). Left atrial size is regarded as reflection of the average effect of left ventricular filling pressure against the LA over time. And has been proposed as marker of diastolic burden (Douglas PS 2003). In addition increased LV filling pressure resulting from disease in myocardial contractility or impairment of myocardial relaxation is considered the main pathophysioligical factor involved in heart failure and contribute to enlargement of the LA (Tsang SM, et al 2002).

\section{OBJECTIVE}

The present study is to investigate the prevalence of increase LA volume in patients with essential HTN and to assess the relationship between increase LA volume and HFnEF.

\section{Method}

This is case control study of 52 patients, 26 patient with history of hypertension (case subject) and 26 without history of hypertension 
(control subject), data were collected through interview cases and controls, physical examination done by the study physician.

Patients were included if they were older than 18 year fulfilled the diagnostic criteria of hypertension (Mancia G, et al 2013).

Exclusion criteria included coronary heart disease, zongenital heart disease, cardiomyopathy, severe anemia, valvular heart disease, hyperthyroidism, Permanente pacemaker implantation or atrial fibrillation.

Transthorsic echocardiography was performed in all subjects. LVEF was estimated using the Simpson rule (Lang RM., et al 2005).

Mitral inflow was assessed by pulsed-wave Doppler echocardiography from the apical fourchamber view, with the Doppler beam aligned parallel to the direction of flow and with sample volume of 1-2 $\mathrm{mm}$ at the mitral tips. From the mitral inflow profil, $\mathrm{E}_{-}$and $\mathrm{A}_{\text {_ }}$ wave velocities, deceleration time (DT) and the E/A ratio were measured (Lang RM. Et al 2005).

LA diameter was measured using M-mode, from the posterior aortic wall to the posterior left atrial wall, in the parasternal long -axis view at end-ventricular systole (ie; just before the mitral valve opening), left atrial enlargement was defined as left atrial diameter of $4.1 \mathrm{~cm}$ or greater in men or $3.9 \mathrm{~cm}$ or greater in women, left atrial diameter below these value defined normal LA size (Lang MR, et al 2005).

Two- dimension guided M- mode measurement of LV end -diastolic dimension (LVDd), inter

\section{RESUlt}

ventricular septum (IVS) thickness and posterior wall (PW) thickness were gained in the LV minor axis at end diastole (Lang MR, et al 2005).

Based on the suggestion of (Devereux RB; et al. 1986), the following equation was applied to determine the LV mass in gram, where the mass can be determined from short-axis dimension using simple geometric cubic formula without measuring the major axis of LV.

$\mathrm{LV}$ mass $=0.8 \times 1.04\left[\left(\mathrm{LVID}+\mathrm{PWT}+\mathrm{IVST}^{3}{ }^{3}\right.\right.$ $\left.\mathrm{LVID}^{3}\right]+0.6$

Where LVID is the LV internal dimension, PWT is the posterior wall thickness, and IVST is the inter ventricular thickness.

The LV mass index was obtained by dividing the LV mass by the body surface area.

Left atrial volume was measured using the modified Simpsons method, maximum LA area, except for the confluence of pulmonary veins and the LA appendage were traced in apical 2and 4 - chamber view at end systole of the LV.

LAVI was calculated as LA volume/ body surface area (Lang RM, et al 2005).

Other various risk factor: BP measurement in the right arm, cigarette smoking to be quantified based on daily consumption and duration of smoking. Blood biochemistry analysis was made; FBS, cholesterol, LDL, HDL, TG, CBC

STATISTICAL ANALYSIS: Was performed by using SPSS software (Version 12) difference among groups was analyzed by (t-test) and $P$ value 0.05 was considerable significant.

Table1. Comparison of clinical characteristic between patient with and without hypertension

\begin{tabular}{|l|l|l|l|}
\hline & Control $(\mathrm{n}=26)($ mean \pm SD $)$ & Hypertensive $(\mathrm{n}=26)(\mathrm{mean} \pm \mathrm{SD})$ & P. value \\
\hline Age & $66 \pm 17$ & $69 \pm 18$ & $\mathrm{NS}$ \\
\hline Diabetes & $8(30 \%)$ & $4(15 \%)$ & $\mathrm{NS}$ \\
\hline Smoking & $9(34 \%)$ & $11(42.3 \%)$ & $\mathrm{NS}$ \\
\hline BMI $\left(\mathrm{kg} / \mathrm{m}^{2}\right)$ & $23.2 \pm 3.4$ & $26 \pm 4.5$ & 0.004 \\
\hline BSA $\left(\mathrm{m}^{2}\right)$ & $1.81 \pm 0.028$ & $1.83 \pm 0.19$ & $\mathrm{NS}$ \\
\hline SBP $\mathrm{mmHg}$ & $136.3 \pm 15.2$ & $148.2 \pm 19.1$ & $<0.001$ \\
\hline DBP $\mathrm{mmHg}$ & $82.1 \pm 96$ & $85.9 \pm 11.7$ & 0.03 \\
\hline Total cholesterol mmol/L & $5.22 \pm 1.15$ & $5.31 \pm 1.21$ & $\mathrm{NS}$ \\
\hline Triglyceride Mmol/L & $1.64 \pm 0.75$ & $1.76 \pm 0.76$ & $\mathrm{NS}$ \\
\hline FBS mg/dl & $93.5 \pm 19.97$ & $97.2 \pm 24.84$ & $\mathrm{NS}$ \\
\hline
\end{tabular}

$B M I=$ body mass index; $B S A=$ body surface area; $S B P=$ systolic blood pressure; $B P=$ diastolic blood pressure; $F B S=$ fasting blood sugar

The mean age was $69 \pm 18$ year in the hypertensive group and $66 \pm 17$ in the control group. There was no difference in mean age between the two groups. There is no significant difference in sex distribution and diabetes among groups. The hypertensive group had a significant higher systolic blood pressure and body mass index than in control group. $(148.2 \pm 19.1$ vs $135.3 \pm 15.2, \mathrm{P}<0.001),(26 \pm 4.5$ vs 23.2 \pm 3.4 , P 0.004 respectively). All smoker were male without significant difference among groups. 
Left Atrial Enlargement is an Early Signs of Hypertensive Heart Disease

Table2. Shows Echo parameter in the hypertensive group and control group

\begin{tabular}{|l|l|l|l|}
\hline & Control & Hypertensive & P \\
\hline LAD mm & $34.5 \pm 3.4$ & $38 \pm 5.2$ & $<0.001$ \\
\hline LVEF $\%$ & $68 \pm 9$ & $70 \pm 11$ & NS \\
\hline FS cm & $38 \pm 7$ & $42 \pm 9$ & NS \\
\hline LVEDD $(\mathrm{cm})$ & $4.8 \pm 0.5$ & $4.9 \pm 0.7$ & NS \\
\hline LVESD $(\mathrm{cm})$ & $3.04 \pm 0.4$ & $2.92 \pm 0.7$ & NS \\
\hline LV mass g & $150 \pm 31$ & $174 \pm 46$ & $<0.0001$ \\
\hline LV mass /height $(\mathrm{g} / \mathrm{m})$ & $94 \pm 19$ & $107 \pm 29$ & 0.001 \\
\hline LVMI $\left(\mathrm{g} / \mathrm{m}^{2}\right)$ & $95 \pm 16$ & $106 \pm 24$ & 0.001 \\
\hline LAV $(\mathrm{ml})$ & $41.7 \pm 13.8$ & $55.5 \pm 15.5$ & $<0.001$ \\
\hline LAVI $\left(\mathrm{ml} / \mathrm{m}^{2}\right)$ & $22.2 \pm 6.3$ & $28.5 \pm 7.2$ & $<0.001$ \\
\hline Mitral peak E $(\mathrm{cm} / \mathrm{s})$ & $72.3 \pm 17$ & $89.7 \pm 25$ & $<0.001$ \\
\hline Mitral peak A $(\mathrm{cm} / \mathrm{s})$ & $82.5 \pm 18$ & $86.2 \pm 22$ & $\mathrm{NS}$ \\
\hline E/A ratio & $1.2 \pm 0.4$ & $0.9 \pm 0.3$ & $<0.001$ \\
\hline DT $(\mathrm{cm})$ & $239 \pm 42$ & $201 \pm 49$ & $<0.001$ \\
\hline EF $(\%)$ & $68 \pm 9$ & $70 \pm 11$ & $\mathrm{NS}$ \\
\hline
\end{tabular}

Abbreviations: $L A D=$ left atrial diameter; $L V E F=$ left ventricular ejection fraction; $F S=$ fractional shortening; $L V E D D=$ left ventricle end diastolic diameter; LVESD=left ventricular end systolic diameter; LVMI=left ventricular mass index; $L A V=$ left atrial volume; $L A V I=l e f t$ atrial volume index; DT=deceleration time.

The average left atrial dimension was $34.5 \pm 3.4$ for normotensive group and was significantly higher, at $38 \pm 5.2$ in the hypertensive group $(\mathrm{P}<0.01)$.

There was no difference in the ejection fraction, percent fractional shortening, end-diastolic or end - systolic dimension.

Left ventricle mass, left ventricular mass/ height and left ventricular mass index were significantly higher in hypertensive group than In control group $(174 \pm 46 \mathrm{~g}$ vs $150 \pm 31 \mathrm{~g}, \mathrm{P}<$ $0.0001107 \pm 2 \mathrm{~g}$ vs $94 \pm 19, \mathrm{p}=0.001106 \pm 24$ vs $95 \pm 16, \mathrm{P}=0.001$ respectively).

Left atrial volume and left atrial volume index were significantly higher in hypertensive group than in control group. $(55.5 \pm 15.5$ vs $41.7 \pm 13.8$, $\mathrm{P}<0.001 \quad 28.5 \pm 7.2 \quad$ vs $\quad 22.2, \quad \mathrm{P}<0.001$ respectively)

Mitral peak E velocity of mitral inflow, E/A ratio and deceleration were significantly greater in the hypertensive group than in control group $(89.7 \pm 25$ vs $72.3 \pm 17, \mathrm{P}<0.0010 .9 \pm 0.3$ vs $1.2 \pm 0.4, \mathrm{P}<0.001201 \pm 49$ vs $239 \pm 42, \mathrm{P}<0.001$ respectively).

Peak A velocity of mitral inflow was not significantly different between the two groups.

\section{DISCUSSION}

The present study demonstrated that LAV, LAVI, LVM, LVMI were increase significantly in hypertensive group compared with control group. In accordance with our study, a recent meta-analysis reported that the prevalence of left ventricle hypertrophy was greater in patients with LA enlargement than those without (Lee KS, et al 2007). (Dreslinski GR, et al 1981) demonstrated reduced left atria emptying index as assisted by M-mode echocardiography in hypertensive patients without ECG evidence of left atrial or left ventricle enlargement, but their patients did have significantly higher echocardiographic left ventricle mass compared to control group.

The present study demonstrated that mitral peak $\mathrm{E}$ velocity of mitral inflow, E/A ratio and deceleration time were significantly greater in hypertensive group than in control group, which was consistent with previous studies (Zile MR, et al 2011; Carson P, et al 2005). LA enlargement was present in majority of patients with HFnEF and might be the best diastolic function prognostic index (Sokolow M, et al 2001) while (Park SM, et al 2009) reported that LA volume was strongly correlated with the degree of diastolic dysfunction. Another study (Ohtania T, et al 2012) found that the higher LA volume index in HFnEF with the diastolic wall strain $\leq 0.03$ might be a useful marker for assessing LV diastolic function. Moreover, in the strong heart study (Kizer JR, et al 2006), LA diameter was proved to be independent predictor of incident cardiovascular events. This relationship may be explained by several potential mechanisms firstly function of LA and ventricle are known to be interactional during the LV systolic phase, the LA acts as reservoir, while in early $\mathrm{LV}$ diastolic, the LA works as conduit for the influx of blood to the left ventricle .Consequently, LA contracts for LV filling in late diastolic 
phase thus, it is credible that increase LA size plays important role in the development of LV diastolic dysfunction (Russo $\mathrm{C}$,et al 2012 ; Lee JS ,et al 2012).

The European association of echocardiography had already included LA volume index into the diagnostic criteria of diastolic heart failure (Kindermann M, et al 2007).

In our study there was no difference in the mean age between two groups.

Some studies (Gardin JM, et al 1979; Triposkidis F, et al 1995) reported that the LA size would naturally increased with age. These observations are supported by evidence that $70 \%$ of patients with atrial fibrillation are 65 year or older (Benjamin ET, et al 1994). Therefore senescence can cause alteration that would eventually culminate with LA dilation and dysfunction, thus increasing the predisposition to atrial arrhythmias (Gosselink AT, et al 1993). However these studies utilized M-mode derived parameter to evaluate atrial dimension, which is technique that has been shown to be geometrically less exact. (Thomas $\mathrm{L}$, et al 2002) and did not find variation in LAV produced by aging when utilizing Simpsons method, thus suggesting that the confirmation of LA enlargement indicates a pathological manifestation, and no a physiological aging process.

\section{CONClusion}

Early detection of LA enlargement may identify patients at higher cardiovascular risk and promote appropriate prevention strategies. The finding in our study indicate that echocardiography assessment is simple, non invasive, safe and easily available tool to identify asymptomatic hypertensive patients who have left ventricle hypertrophy, left atrial enlargement, left ventricle diastolic dysfunction before abnormalities detected by clinical examination.

\section{REFERENCES}

[1] Aurigemma GP, Gaasch WH. Diastolic heart failure. N Engl J Med 2004; 351:1097-105.

[2] Carson P, Massie BM, Mckelvie R, et al. The irbesartan in heart failure with preserved systolic function (I-PRESERVE) trial: rational and design. J Card Fail. 2005; 11:576-585.

[3] DATASUS. Departmento de informatica do SUS Ministerio da SAude. Disponivel em:< http:/www.datasus.gov.br>.

[4] Devereux RB, Alonso DR, Lutas EM, et al. echocardiographic assessment of left ventricular hypertrophy: comparison to necropsy finding. Am J Cardio. 1986: 57: 450458.

[5] Douglas PS. The left atrium: a biomarker of chronic diastolic dysfunction and cardiovascular disease risk. J Am Coll Cardiol. 2003; 42: 1206-1207.

[6] Dreslinski GR, Frolich ED, Dunn FG, Messerli FH, Suarez DH, Reisin V. Echocardiographic diastolic ventricular abnormality in hypertensive heart disease: atrial empting index. Am J Cardiol 1981: 47:1087

[7] Gardin JM, Henry WL, Savage DD, Ware JH, Burn C, Borer JS. Echocardiographic measurements in normal subjects: evaluation of an adult population without clinically apparent heart disease. J Clin Ultrasound 1979:7:439.

[8] Gosselink AT, Crijins HJ, Hamer HP, Hillege $\mathrm{H}$, Lie KI. Changes in left and right atrial size after cardio version of atrial fibrillation: role of mitral valve disease. J Am Coll Cardiol 1993; 22:1666-72.

[9] Kannel WB, Castelli WP, McNamara PM, Mckee PA, Fein lab M. Role of blood pressure in the development of congestive heart failure. N Engl J Med 1972; 287:781.

[10] Kindermann M. How to diagnose diastolic heart failure: a consensus statement on diagnosis of heart failure with normal left ventricular ejection fraction by the heart failure and Echocardiography Association of European Society of Cardiology. Eur Heart J. 2007; 28:2686; author reply 2686-2687.

[11] Kizer JR, Bella JN, Palmieri V, et al, left atrial diameter as an independent predictor of first clinical cardiovascular events in middle-aged and elderly adults: the Strong Heart Study (SHS). Am Heart J 2006; 151:412-418.

[12] Lang Rm, Bierig M, Devereux RB, et al Recommendation for chamber quantification are part from the American society of Echocardiography and standard committee and chamber quantification writing group, developed in conjunction with European Association of Echocardiography A branch of European society of Cardiology Jam soc Echocardiography 2005;18:1440-63.

[13] Lee JS, Shim CY Wi J, et al, left ventricular diastolic function is closely associated with mechanical function of the left atrium in patient with paroxysmal atrial fibrillation. Circ J. 2013;77:697-704.

[14] Mancia G,Fagard R, Narkiewicz K, et al. 2013 Practice guideline for the management of arterial hypertension of the European Society of Hypertension (ESH) and European Society of 
Cardiology (ESC): ESH/ESC Task Force for the Management of Arterial Hypertension. J Hypertense.2013; 31:1925-1938.

[15] Munuswamy K, Alpert MA, Martin RH, et al. Sensitivity and specificity of commonly used electrocardiographic criteria for left atrial enlargement determined by $\mathrm{M}-$. mode echocardiography. Am J Cardiol 1984; 53:829832

[16] Ohtani T, Mohammed SF, Yamamoto K, et al. Diastolic stiffness as assessed by diastolic wall strain is associated with adverse remodeling and poor outcomes in heart failure with preserved ejection fraction. Eur Heart J. 2012; $33: 1742-1749$

[17] Park SM, Park SW, Casaclang-Verzosa G, et al. Diastolic dysfunction and left atrial enlargement as contributing factors to functional mitral regurgitation in dilated cardiomyopathy: data from the Acron trial. Am heart J, 2009; 157:762-710.

[18] Russo C, Jin Z, Homma S, et al. left atrial minimum volume and reservoir function as correlates of left ventricular diastolic function; impact of left ventricular systolic function. Heart. 2012; 98:813-820.

Citation: Hanan K. G. Altalhi, Asgad A. Abdalgbar. Left Atrial Enlargement is an Early Signs of Hypertensive Heart Disease. ARC Journal of Nutrition and Growth. 2019; 5(2):1-5. DOI: dx.doi.org/ 10.20431/2455-2550.0502001.

Copyright: () 2019 Authors. This is an open-access article distributed under the terms of the Creative Commons Attribution License, which permits unrestricted use, distribution, and reproduction in any medium, provided the original author and source are credited. 